\title{
USO DE MARCADORES PARASITOLÓGICOS E IMUNOLÓGICOS NA SELEÇÃO DE OVELHAS RESISTENTES ÀS PARASITOSES GASTRINTESTINAIS
}

\author{
Fernanda Rosalinski-Moraes ${ }^{1}$, Cristina Santos Sotomaior ${ }^{2}$, \\ Elizabeth Moreira dos Santos Schmidt ${ }^{3}$, Vanete Thomaz-Soccol ${ }^{1}$ \\ 1 Universidade Federal do Paraná - vanetesoccol@gmail.com \\ 2 Jontifícia Universidade Católica do Paraná \\ 3 Universidade Estadual Paulista - Campus de Botucatu
}

\begin{abstract}
RESUMO: Este trabalho foi realizado com objetivo de avaliar a possibilidade de identificar ovelhas resistentes e susceptíveis às parasitoses por meio de um marcador parasitológico (direto), de marcadores imunológicos (indiretos) ou pela associação entre ambos. Vinte ovelhas foram acompanhadas por coletas mensais de sangue e fezes no período de novembro de 1998 a maio de 1999. O marcador parasitológico utilizado foi o número de ovos de helmintos por grama de fezes (OPG); os marcadores imunológicos foram o número de eosinófilos sanguíneos, imunoglobulinas $\mathrm{G}$ ( $\mathrm{IgG}$ e e $\mathrm{E}(\mathrm{IgE})$ anti-Haemonchus contortus. As ovelhas puderam ser classificadas como resistentes ou susceptíveis pelo OPG. Pelo o número de eosinófilos ou pela lgE específica utilizados concomitantemente com o OPG foi possível identificar ovelhas resistentes e susceptíveis ao parasitismo gastrintestinal. O número de eosinófilos sanguíneos foi o único marcador imunológico que permite de classificar as ovelhas indiretamente nos mesmos grupos obtidos pelo o OPG.
\end{abstract}

Palavras-chave: eosinófilos; imunoglobulina G; imunoglobulina E; resistência aos parasitos

\section{USAGE OF PARASITOLOGICAL AND IMMUNOLOGICAL MARKERS FOR THE SELECTION OF EWES RESISTANT TO GASTROINTESTINAL PARASITES}

\begin{abstract}
This work was conducted to verity the possibility to identify adult sheep that are resistant to parasites by using a parasitological marker (direct), immunological markers (indirect) or by the association of both types of markers. Twenty ewes were sampled monthly for blood and faeces, from July of 1998 to June of 1999. Faecal egg counts (FEC) was chosen as parasitological marker. The number of peripheral eosinophils, IgE and IgG anti-Haemonchus contortus were used as immunological markers. Sheep could be classified as resistant or susceptible by FEC. Both peripheral eosinophils and specific IgE data could be joined to FEC in order to identify resistant or susceptible animals. The number of peripheral eosinophils was the only immunological maker that was able to classify high and low FEC ewes in two different groups.
\end{abstract}

Key Words: eosinophils; immunoglobulin G; immunoglobulin E; resistance to nematodes 


\section{INTRODUÇÃO}

A verminose gastrintestinal é uma das principais causas de perdas produtivas em rebanhos ovinos (TorresAcosta e Hoste, 2008; Thomaz-Soccol et al., 2004). Seus principais efeitos são observados em cordeiros e em fêmeas adultas no período de lactação (Sotomaior et al. 2009).

Uma das formas de minimizar os prejuízos com medicamentos e retardar o processo de resistência antihelmíntica é a identificação de animais que sejam resistentes aos helmintos gastrintestinais (FAO, 2003; Amarante, 2004). No entanto, estratégias para este processo devem ser estudadas considerando as particularidades de cada categoria animal.

As ovelhas são a base de um rebanho, uma vez que elas são responsáveis pela produção dos cordeiros que serão abatidos. Por este motivo, normalmente se considera que a cada ano, apenas uma média de 10 a $20 \%$ das fêmeas de um plantel devam ser descartadas e substituídas (Gomes, 2006). A escolha dos animais a serem descartados normalmente é realizada em função da idade, baixa produtividade, ocorrência de defeitos genéticos e de portadores de doenças infecto-contagiosas (Granados et al., 2006).

Tendo em vista que a maioria das ovelhas de um plantel se mostra resistente aos parasitos gastrintestinais (Torres-Acosta e Hoste, 2008; Sotomaior et al. 2009), a identificação das fêmeas susceptíveis por meios eficientes e economicamente viáveis pode ser mais um critério a ser considerado no momento de realizar o descarte de matrizes, como alternativa importante para diminuir o impacto da verminose gastrintestinal nos rebanhos. Este trabalho tem por objetivos avaliar a possibilidade de identificar ovelhas resistentes e susceptíveis às parasito- ses por meio de um marcador parasitológico (direto), de marcadores imunológicos (indiretos) ou pela associação entre ambos.

\section{MATERIAL E MÉTODOS}

Foram acompanhadas 20 ovelhas pertencentes ao Quartel General do Exército da Quinta Região Militar, Curitiba, no período entre 10 de novembro de 1998 e 01 de junho de 1999. Todas as fêmeas eram mestiças Suffolk de vários graus de sangue, com idade de um a oito anos. Na estação de monta de 1998, todas as ovelhas foram cobertas por um carneiro Suffolk. Os cordeiros, produtos deste cruzamento, nasceram entre nos meses de junho e julho, e seu desmame foi realizado conjuntamente, em 06 de outubro de 1998. No ano de 1999, as ovelhas foram cruzadas com um carneiro Hampshire Down a partir de janeiro. Desta forma, o período experimental compreendeu 0 acompanhamento das fêmeas ovinas de um mês após o desmame até o terço final de gestação (perído seco).

As ovelhas dividiram os mesmos piquetes com os borregos desmamados, pastejando continuamente uma área de grama estrela (Cynodon spp.) no verão e Azevém (Lolium multiflorum) no inverno. Os animais eram recolhidos a um galpão fechado durante a noite e ao meio dia, onde recebiam suplementação de concentrado e mineralização. Água era fornecida à vontade tanto nas instalações quanto nos piquetes. Todos os animais permaneceram constantemente nas mesmas pastagens, sujeitos à infecção natural por nematódeos. Antes do experimento, foi realizado hemograma completo de todos os animais envolvidos a fim de verificar seu estado sanitário. Todos os resultados foram considerados dentro dos valores 
de referência para a espécie ovina (Jain, 1993).

As coletas de fezes foram realizadas a cada 28 dias, no período de novembro de 1998 a maio de 1999. As fezes foram coletadas com sacos plásticos, diretamente do reto de cada animal. As coletas de sangue total e soro foram realizadas na mesma data das coletas de fezes, sempre por volta das oito horas da manhã, por venopunção jugular. Para a coleta de sangue total foram utilizados tubos à vácuo de $3 \mathrm{~mL}$ com EDTA, e para o soro, tubos a vácuo de $5 \mathrm{~mL}$. As amostras de soro foram obitdas por centrifugação e mantidas a $-20^{\circ} \mathrm{C}$ até a realização do ensaio-imunoenzimático. As amostras de sangue total foram identificadas e levadas ao laboratório e a contagem de eosinófilos foi realizada no máximo até 12 horas após a coleta.

Para estimativa do OPG (número de ovos de helmintos por grama de fezes), foi utilizada a técnica de Gordon e Whitlock (1939), sensível para 100 OPG. Para identificar os gêneros de parasitos prevalentes em cada pico de parasitismo, foi realizada a cultura de larvas. Para isto, um pool de amostras obtido a cada coleta foi homogeneizado, umedecido e acrescido de cepilho. Cada pool foi incubado a $25^{\circ} \mathrm{C}$ por 15 dias. As larvas foram recuperadas do cultivo pelo método de Rugai et al. (1954) e identificadas com a chave proposta por Ueno e Gonçalves (1994).

A contagem dos eosinófilos foi feita pelo método direto (Lima et al., 1985), em câmara de Fucks-Rosenthal, utilizando diluente de Pilot Modificado (MacFarlane e Cecil, 1951). A leitura foi feita em microscópio óptico, no aumento de 400 vezes. O número de eosinófilos por $\mathrm{mm}^{3}$ de sangue foi obtido pela multiplicação da média de eosinófilos contados nos dois retículos pelo fator de correção $(6,25)$.

Para determinação dos níveis de IgG anti-Haemonchus contortus especí- fica, foi utilizado 0 ensaio imunoenzimático (ELISA) indireto, conforme descrito em RosalinskiMoraes et al. (2008). As placas de poliestireno foram sensibilizadas overnight a $5^{\circ} \mathrm{C}$ com $100 \mathrm{~mL}$ de solução de antígeno somático de Haemonchus contortus (H.c.) adultos $(5 \mu \mathrm{g} / \mathrm{mL}$ em tampão carbonato-bicarbonato, $\mathrm{pH} 9,6$ ), lavadas, e bloqueadas com $150 \mu \mathrm{L}$ por poço de uma solução de $2 \%$ de caseína bovina, por uma hora, a $37^{\circ} \mathrm{C}$. As amostras de soro foram acrescentadas em duplicatas, diluídas 1:80 em tampão de incubação (caseína 2,5 $\mathrm{mg} / \mathrm{mL}$; tween $200,5 \mu \mathrm{l} / \mathrm{mL}$ ) e incubadas por uma hora a $37^{\circ} \mathrm{C}$. Seis lavagens foram procedidas para remover as proteínas do soro. Cem microlitros de conjugado anti-IgG ovina (SIGMA A3415), diluído 1/1000 em tampão de incubação, foram adicionados a cada poço e incubado a $37^{\circ} \mathrm{C}$ por uma hora. Após novas seis lavagens, foram acrescentados $50 \mu \mathrm{l}$ de substrato OPD - Ortofenilenodiamino (SIGMA P6787) (2 mg em 10,5 mL de tampão fosfato). Dois microlitros de peróxido de hidrogênio foram utilizados para catalisar a reação. A placa foi incubada em temperatura ambiente por 15 minutos e a reação foi inibida com a adição de $50 \mu \mathrm{l}$ de ácido sulfúrico a $5 \%$ por poço. A leitura foi realizada em leitor de placas com filtro de $492 \mathrm{~nm}$.

Para determinação do nível de $\lg \mathrm{E}$ específica, foi adaptada a técnica descrita por Shaw et al. (1998). Antes da realização do ensaio, os soros-teste foram submetidos à precipitação por sulfato de amônio saturado (SAS), a fim de eliminar as moléculas de $\lg G$ presentes na amostra. Inicialmente, foi preparada uma solução de SAS em salina, no dobro da concentração final $(39 \%)$. Esta foi adicionada no mesmo volume da amostra a ser submetida à precipitação. A mistura foi homogeneizada e as amostras foram centrifugadas a $13.000 \mathrm{rpm}$ por 10 minutos. O sobrenadante foi colhido e armazenado 
a $5^{\circ} \mathrm{C}$ em novos tubos. Cada amostra resultante da precipitação em SAS foi diluída 1:20 em solução fisiológica com $0,1 \%$ Tween 20.

As placas de poliestireno foram sensibilizadas e bloqueadas conforme descrito para o ensaio para detecção de IgG específica. A seguir, $100 \mu \mathrm{l}$ de cada amostra de soro (precipitada em SAS e diluída1:20) foram adicionadas em duplicata, e incubada overnight em temperatura ambiente. Após seis lavagens, os anticorpos monoclonais (mAbs) anti-lgE ovina YD3 e XB6, produzidos a partir de células de camundongos imunizados (Shaw et al., 1996), foram adicionados na concentração de $2,5 \quad \mu \mathrm{g} \cdot \mathrm{mL}^{-1} \quad \mathrm{e}$ incubados por duas horas em temperatura ambiente. Novas seis lavagens foram procedidas para remoção dos mAbs que não se aderiram na placa. A diluição do conjugado peroxidase-anti-lgG (cadeia $\gamma$ ) murina (SIGMA A3673), bem como os passos subseqüentes foram idênticos ao descrito para o ensaio para detecção de $\lg \mathrm{G}$ anti-H.c.

As 20 ovelhas foram desverminados por ocasião do desmame (dia 06 de outubro) com $200 \mu \mathrm{g} \mathrm{kg}{ }^{-1}$ de Moxidectina (Cydectin $\AA$ Cyanamid Química do Brasil Ltda.). Esta dosificação teve como objetivo deixar os animais em condições semelhantes de parasitose para o acompanhamento. Durante o acompanhamento, foram procedidas novas dosificações antihelmínticas sempre que a média de OPG ultrapassasse 1500, com o mesmo princípio ativo e dose.

Todas as análises estatísticas foram realizadas no programa Statistica, versão 5.0, exceto pelo teste de Bartlett para determinação da homogeneidade das variâncias, realizado no MSTAT-C, versão 2.10. Os dados de OPG foram transformados no logaritmo decimal do valor mais uma unidade $(\log (O P G+1))$; o número de eosinófilos no sangue periférico (EOSINO), lgE e $\lg G$ específicas, no logaritmo decimal do valor (log(EOSINO); $\log (\lg E) ; \log (\lg G)$.

O OPG foi considerado marcador parasitológico; as variáveis eosinófilos, IgE e IgG foram consideradas marcadores imunológicos. Para 0 estudo do comportamento de cada variável no rebanho, os dados foram submetidos à Análise de Variância, considerando um delineamento inteiramente casualizado, onde os animais representavam as repetições e as diferentes coletas os tratamentos. As médias de cada coleta foram comparadas pelo teste de Duncan, $\mathrm{P}<0,05$. As correlações entre os marcadores estudados foram obtidas pelo teste não paramétrico de Spearman e consideradas significativas quando $P$ foi menor que 0,05 .

Para a seleção dos animais, diferentes combinações entre as variáveis foram submetidas à análise de cluster. A escala adotada foi a distância euclidiana, que corresponde à distância geométrica entre as unidades no espaço multidimensional. Os clusters formados foram ligados com bases nos vizinhos distantes (Complete linkage). Como as variáveis utilizadas para o agrupamento apresentavam diferentes unidades, os dados brutos (sem transformação logarítmica) foram "estandarizados" antes de ser submetidos à análise.

Uma vez obtidos os grupos resistente e susceptível pela análise de cluster, as médias de cada grupo para as variáveis analisadas $(\log (O P G+1)$; $\log (E O S I N O) ; \log (\lg E)$ e $\log (\lg G)$ foram comparadas pelo teste $t$ de Student para amostras não pareadas.

\section{RESULTADOS E DISCUSSÃO}

Os exames coproparasitológicos revelaram a predominancia de ovos estrongiliformes durante todo o período, embora pequenas quantidades de ovos de Strongyloides papillosus, 
(a)

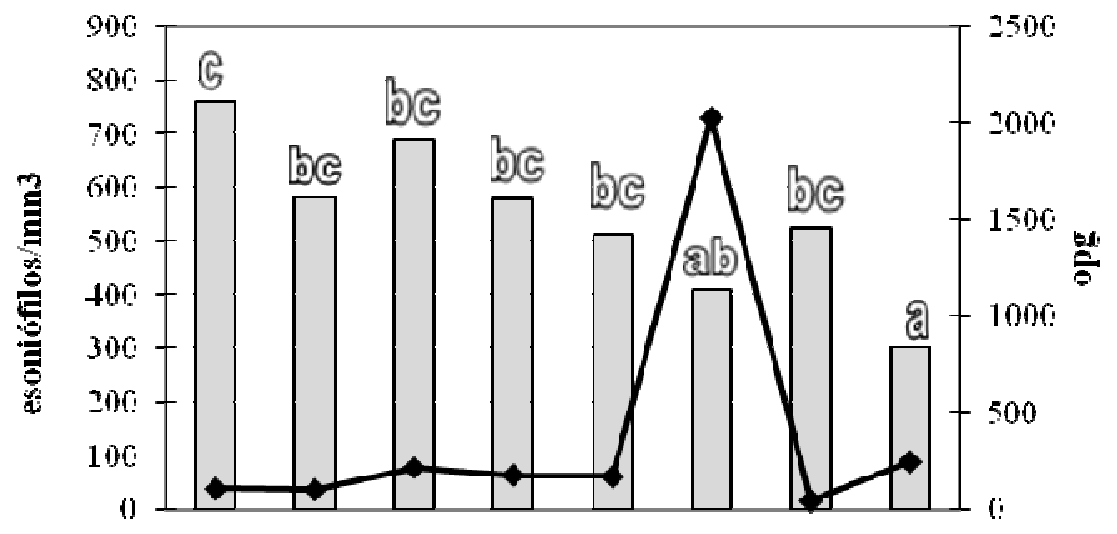

(b)

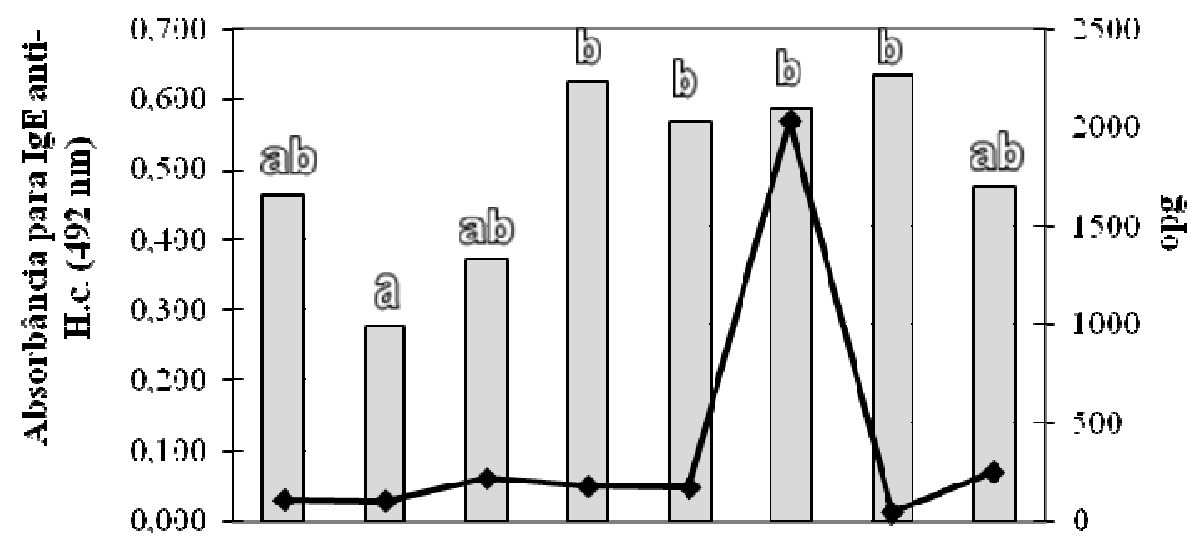

(c)

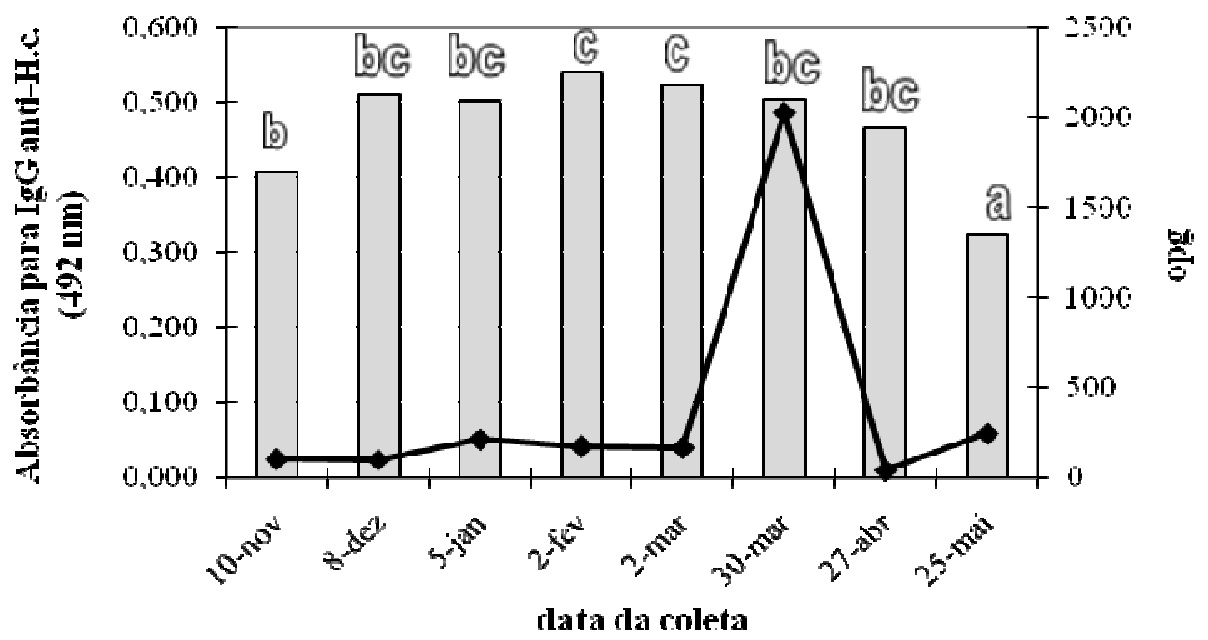

Figura 1 - Média mensal de ovos de helmintos por grama de fezes (OPG-linhas), eosinófilos por milímetro cúbico de sangue (a), absorbância para lgG (b) e lgE anti-Haemonchus contortus (c) de ovelhas adultas, no período de novembro de 1998 a maio de 1999.

As letras indicam diferenças nas médias para o teste de Duncan para as variáveis imunológicas $(\mathrm{P}<0,05)$. A média da variável OPG diferiu significativamente apenas na coleta de 30 de março. 
Nematodirus spp., Moniezia sp. e oocistos de Eimeria spp. também tenham ocorrido ao longo do estudo. A média de OPG se manteve baixa durante a maior parte do acompanhamento, com um aumento na coleta de 30 de março, quando a média de eliminação foi de $2028,57 \pm 3511,97$ OPG, única coleta cuja média do rebanho foi considerada diferente das demais pelo teste de Duncan $(\mathrm{P}<0,05)$ (Figura 1). Por este motivo, o rebanho foi tratado com moxidectina $(0,02 \mathrm{mg} / \mathrm{kg}$, via subcutânea), que resultou em uma redução de 99,26\% no OPG 14 dias após o tratamento.

Nas culturas de larvas, foi verificada predominância dos gêneros Haemonchus spp. com prevalência média de $90 \%$ das larvas encontradas. Também foram assinaladas larvas de Trichostrongylus spp., Teladorsagia sp., Nematodirus spp. e Cooperia spp. Estes achados estão de acordo com O'Connor et al. (2006), que relataram a predominância do gênero Haemonchus nas regiões tropicais e subtropicais com verões chuvosos.

O número de eosinófilos periféricos apresentou-se alto no mês de novembro, com média de 762,18 \pm 618,49 eosinófilos por $\mathrm{mm}^{3}$ de sangue (Figura 1a), e se manteve constante de dezembro a março. Concomitante ao pico de parasitismo de 30 de março foi observada uma redução no número de eosinófilos circulantes, com média de $410,62 \pm 178,82$ células por $\mathrm{mm}^{3}$. Esta alteração pode ter sido relacionada à migração para a mucosa gastrintestinal, induzida pela liberação de IL-5, em decorrência do estímulo parasitário (Tizard, 2009). Foi documentada a expressão de mRNA de IL-5, juntamente com IL-4 e IL-13 nos linfonodos mesentéricos de cordeiros resistentes infectados com Haemonchus contortus (Terefe et al. 2007). Pernthaner et al. (2006) relataram um aumento significativo dos níveis desta interleucina na linfa intestinal de ovinos de um ano de idade criados a pasto, quando estes foram desafiados com larvas de Trichostrongylus colubriformis.

Após o tratamento anti-helmíntico, foi observada rápida redução da média de OPG e uma recuperação no nível sanguíneo médio de eosinófilos (Figura1a). Porém, nova diminuição no número de eosinófilos foi registrada na última coleta do acompanhamento e atingiu a média de 302,50 \pm 116,78 eosinófilos por $\mathrm{mm}^{3}$. Este valor poderia estar associado à imuno-depressão peripuerperal, uma vez que a maioria dos animais acompanhados encontravase no último mês de gestação. Valderrábano et al. (2006) também relataram diminuição no número de eosinófilos circulantes em fêmeas ovinas um mês antes do parto.

A média dos valores de absorbância para IgE específica foi baixa nos meses de novembro $(0,462 \pm$ 0,574 ) e de dezembro (Figura 1b). De fevereiro a abril, a média de IgE específica se manteve elevada e constante. Em maio ocorreu nova diminuição nos valores médios de $\lg \mathrm{E}$ anti-H.c. $(0,476 \pm 0,547)$.

Ao contrário do observado com os eosinófilos, houve uma tendência do nível de $\operatorname{lgE}$ específica se manter elevado durante o pico de parasitismo. Pernthaner et al. (2005) observaram que o nível de $\lg$ E específica no soro era proporcional ao encontrado na linfa intestinal de animais parasitados.

Pfeffer et al. (2005) não encontraram diferença significativa nos níveis séricos de $\lg \mathrm{E}$ antiTrichostrongylus colubriformis em ovelhas entre o dia do parto e 30 dias após, mas verificaram níveis colostrais deste anticorpo equivalentes aos séricos. Portanto, os baixos valores de IgE específica observados nas três primeiras coletas podem ser reflexo da transferência passiva destes anticorpos e da imunodepressão lactacional. Se 
Tabela 1 - Correlações de Spearman entre ovos de helmintos por grama de fezes (OPG), eosinófilos circulantes (EOSINO), IgG e IgE anti-Haemonchus contortus de ovelhas adultas, considerando todas as coletas entre novembro de 1998 e maio de 1999 (acima da diagonal) e apenas a coleta de 30 de março de 1999, correspondente ao pico de parasitismo (abaixo da diagonal)

\begin{tabular}{lcccc}
\hline Variável & OPG & EOSINO & $\operatorname{lgE}$ & $\operatorname{lgG}$ \\
\hline OPG & - & $-0,2097^{*}$ & $-0,0341$ & 0,1310 \\
EOSINO & $-0,6418^{*}$ & - & 0,1331 & 0,0221 \\
lgE & $-0,1138$ & 0,2549 & - & $0,1554^{*}$ \\
$\operatorname{lgG}$ & 0,0007 & 0,0316 & $-0,1865^{*}$ & - \\
\hline${ }^{*} \mathrm{P}<0,05$ & & & &
\end{tabular}

esta hipótese for verdadeira, a $\lg E$ específica é a última das variáveis imunológicas a restabelecer seus valores normais após o término da lactação. Este restabelecimento ocorreria somente após longo período de desafio parasitário. É possível que a contaminação do pasto por ovos de helmintos eliminados pelos animais jovens, somada às condições climáticas favoráveis ao desenvolvimento do estádio infectante tenham proporcionado um nível de desafio parasitário necessário para a elevação da $\lg E$ sérica.

A diminuição no nível médio de $\operatorname{lgE}$ específica no mês de maio foi acompanhada de redução na média de outras variáveis imunológicas (IgG e eosinófilos periféricos). A diminuição nos níveis médios de todas as variáveis imunológicas na coleta do dia 25 de maio pode ser atribuída à imunodepressão peri-parto, uma vez que a maior parte das fêmeas estavam no quinto mês gestacional.

No início do acompanhamento, a média de absorbância para IgG específica foi de 0,408 \pm 0,092 (Figura 1c). Um pequeno aumento nesta média foi observado em dezembro, com os valores se mantendo constantes até o mês de abril. No mês de maio foi observada uma redução acentuada nos valores de $\operatorname{lgG}$ anti-H.c., atingindo a média de 0,324 $\pm 0,078$.

A baixa média de IgG anti-H.c. observada no início do acompanhamen- to pode estar relacionada à imunodepressão inespecífica que ocorre nas fêmeas durante o período lactacional (Houdijk et al., 2000). Pfeffer et al. (2005) observaram o aumento dos níveis séricos de $\operatorname{lgG}_{1}$ antiTrichostrongylus colubriformis 30 dias após o parto, mas não houve comparação dos níveis deste anticorpo no período periparto e o término da lactação das ovelhas. Portanto, é possível que o restabelecimento total dos níveis de $\lg G$ específica só aconteça após o término do período lactacional. Isso explicaria o aumento na média desta variável a partir da coleta de novembro, um mês após o desmame dos cordeiros. Outra explicação para a baixa absorbância observada na primeira coleta seria os níveis baixos de parasitismo dos animais, resultando em um insuficiente estímulo ao sistema imune.

A manutenção dos níveis de $\lg G$ específica durante os meses de verão e outono pode ser resultado da infecção constante dos animais com $\mathrm{L}_{3}$ na pastagem. A queda destes níveis no mês de maio, tal qual a queda do número de eosinófilos periféricos, pode ser atribuída à imunodepressão periparto.

Quando os dados de OPG, eosinófilos, $\lg \mathrm{E}$ e $\lg \mathrm{G}$ de todas as coletas foram correlacionados entre si e observou-se que tanto eosinófilos quanto $\lg \mathrm{E}$ tendem a ser correlacionados negativamente com o OPG (Ta- 


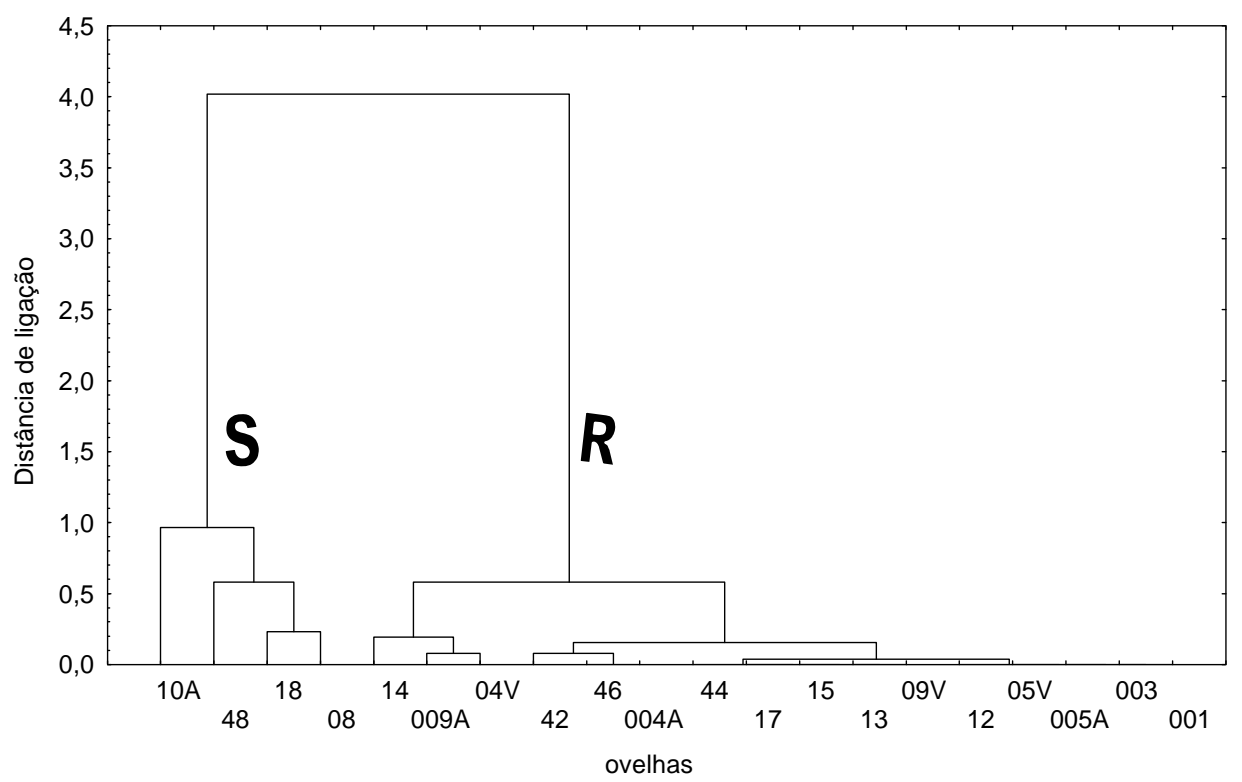

Figura 2 - Dendrograma construído com os dados de contagem de ovos de helmintos por grama de fezes (OPG) da coleta de 30 de março de 1999, correspondente ao pico de parasitismo de outono em ovelhas adultas, demonstrando o grupo de ovelhas resistente (R) e susceptível (S).

bela 1). A IgG não foi correlacionada significativamente com o OPG nem com o número de eosinófilos circulantes, mas foi observada correlação baixa e negativa com a $\lg \mathrm{E}$.

Quando os dados totais de cada variável foram correlacionados, 0 número de eosinófilos sanguíneos foi a variável que obteve maior correlação com o marcador parasitológico. No pico de verminose, uma correlação de $-0,64$ foi obtida entre eosinófilos periféricos e OPG. Isso indica que o grau de parasitismo é diretamente responsável pela migração dos eosinófilos do sangue para a mucosa gastrintestinal. Nível médio de correlação $(r=-0,26)$ entre eosinófilos e OPG também foi detectado por Woolaston et al. (1996) após desafiar borregos de 13 meses de idade, submetidos a prévias infecções a campo.

A correlação obtida entre $O P G$ e IgG divergiu de outros estudos, nos quais correlações negativas entre IgG específica e OPG de nível médio a alto foram detectadas (Douch et al., 1995, 1996; Bisset et al., 1996; Shaw et al., 1999). A correlação positiva entre $\lg G$ e
OPG obtida neste estudo pode ser reflexo de uma provável seleção natural para resiliência. Embora não haja estudos sobre a resposta imune de animais resilientes, pode ser que os altos níveis de IgG indiquem a capacidade do organismo em reconhecer o agente agressor, mas não em expulsálo.

Os baixos valores de correlação obtidos entre as variáveis estudadas podem ser decorrentes da heterogeneidade de resposta imune dos indivíduos. Considerável variação na expressão da imunidade dos ovinos aos helmintos gastrintestinais foi observada em outros estudos (Shaw et al., 1997; GómezMuñhoz et al.,1998). No presente trabalho, a variabilidade pode ter sido evidenciada devido à infecção natural, à baixa amostragem do lote $e$ às diferenças de idade e de raça entre os animais.

Classificação das ovelhas em resistentes e susceptíveis à parasitose gastrintestinal com base no marcador parasitológico (OPG)

Para a análise de cluster, foram elaboradas três hipóteses de agrupa- 
Tabela 2 - Média e desvio padrão do logaritmo das contagens de ovos de helmintos por grama de fezes (OPG), eosinófilos circulantes (Eosino), IgG e IgE anti-Haemononchus contortus das ovelhas classificadas como resistentes e susceptíveis pela análise de cluster realizada com dados de OPG, na coleta de 30 de março de 1998, referente ao pico de parasitismo.

\begin{tabular}{lccccc}
\hline Variável & \multicolumn{2}{c}{ Grupo resistente $(\mathrm{n}=16)$} & \multicolumn{2}{c}{ Grupo susceptivel $(\mathrm{n}=4)$} & \multirow{2}{*}{$\mathrm{P}^{*}$} \\
\cline { 2 - 5 } & Média & Desvio & Média & Desvio & \\
\hline Log (OPG+1) & 3,9581 & 1,2294 & 1,6742 & 0,5013 & 0,00187 \\
Log (Eosino) & 2.6435 & 0,1536 & 0,2809 & 0,0582 & 0,00024 \\
Log (lgE) & $-0,4335$ & 0,5509 & $-0,7353$ & 0,5589 & 0,34131 \\
$\log (\operatorname{lgG})$ & $-0,3219$ & 0,1209 & $-0,2639$ & 0,0285 & 0,36211 \\
\hline
\end{tabular}

${ }^{\star}$ Probabilidade de erro do tipo I em teste T independente

mento baseadas no OPG: (1) dados de todas as coletas; (2) dados da coleta 6 (pico de parasitismo de outono); (3) dados das coletas 5 e 6 . As três hipóteses resultaram em clusters muito semelhantes, capazes de identificar o mesmo grupo de animais resistentes, composto por 16 ovelhas, e o mesmo grupo de animais susceptíveis ao parasitismo, composto por quatro fêmeas (Figura 2).

A diferença da média de do log $(\mathrm{OPG}+1)$ e do número de eosinófilos sanguíneos foi significativa entre os grupos resistente e susceptível $(P<0,05)$ no pico de parasitismo. Não foi observada diferença significativa entre os grupos para a média dos logaritmos de IgE e lgG específica (Tabela 2).

Classificação das ovelhas em resistentes e susceptíveis à parasitose gastrintestinal com base em mais de um marcador

Para a seleção das ovelhas baseada em mais de um marcador, foram comparadas as seguintes hipóteses: (1) dados de OPG, eosinófilos sanguíneos, $\lg E$ e $\lg G$ de todas as coletas; (2) dados de OPG, eosinófilos sanguíneos, $\lg E$ e $\lg G$ da coleta 6 (pico de parasitismo); (3) dados de OPG e eosinófilos da coleta 6; (4) dados de OPG e IgE da coleta 6; (5) dados de OPG e IgG da coleta 6.

As hipóteses de 1 a 4 dividiram os animais de formas distintas, mas todas foram capazes de separar um mesmo grupo de quatro ovelhas de baixo OPG. Estas foram as mesmas ovelhas identificadas como susceptíveis utilizando o marcador parasitológico. Desta forma, estas hipóteses foram capazes de segregar as ovelhas susceptíveis do grupo resistente.

A última hipótese resultou em dois grupos: o grupo A, que compreendeu os animais de alta $\operatorname{lgG}$, foi subdividido em dois subgrupos. $O$ subgrupo $A_{1}$ compreendeu os animais cujos valores de OPG foram elevados (susceptíveis) e - $A_{2}$, animais com valores baixos de OPG. O grupo B compreendeu animais de baixa IgG. Como os grupos primários formados (A e B) mantinham animais de baixo OPG, não se pôde obter grupos resistentes e susceptíveis bem delimitados (Figura 3).

Classificação das ovelhas em resistentes e susceptíveis com base em marcadores imunológicos

A fim de observar o comportamento dos marcadores imunológicos como ferramentas de seleção indireta para animais resistentes (de baixo OPG), os valores de eosinófilos, IgE e IgG específica foram submetidos à análise de cluster. Para cada variável foram construídos dois clusters, um relacionando dados do pico de parasitismo (coleta 6) com a coleta imediatamente anterior (coleta 5), e outro com a coleta imediatamente posterior (coleta 7).

Tanto para IgG quanto para $\lg E$ específica, nenhum cluster foi capaz de reunir os animais susceptíveis em um 


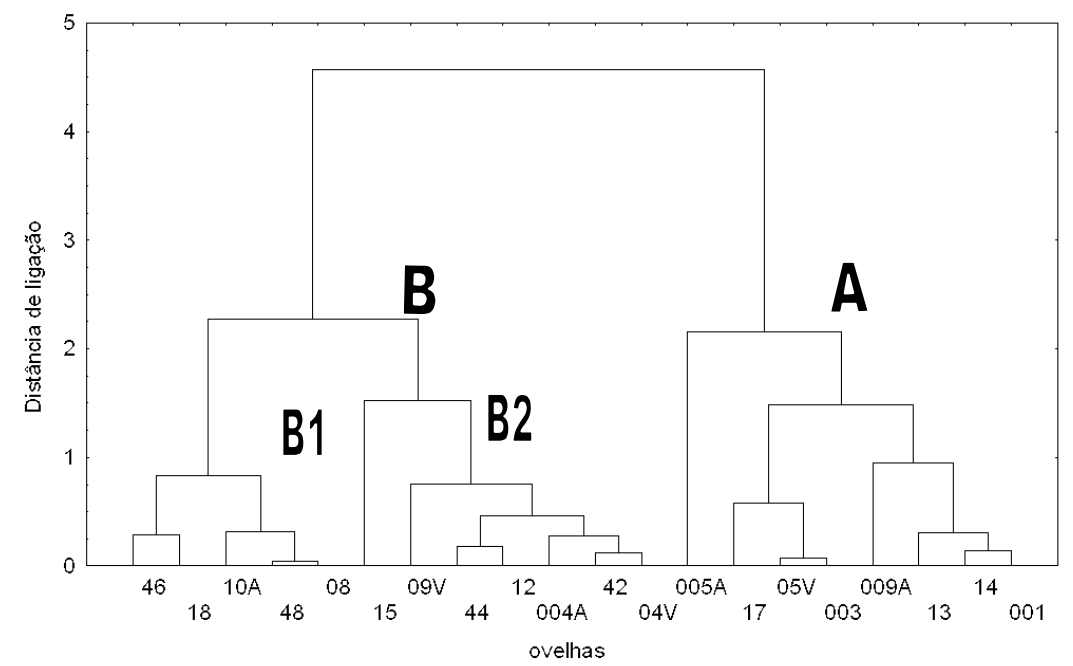

Figura 3 - Dendrograma construído com os dados de contagens de eosinófilos por $\mathrm{mm}^{3}$ de sangue obtidos na quinta e sexta coleta de ovelhas adultas, realizadas em 02 e em 30 de março de 1999, respectivamente.

mesmo grupo. Nas duas hipóteses formuladas para os eosinófilos, os quatro animais considerados susceptíveis pelo OPG foram incluídos no grupo de menores valores para eosinófilos (Figura 3, grupo B1).

Quando o OPG foi utilizado como marcador, $80 \%$ do lote acompanhado foi enquadrado no grupo resistente. Isto foi possível uma vez que a população parasitária tende a apresentar uma distribuição binomial negativa entre hospedeiros, com a predominância de animais com baixa carga parasitária (Torres-Acosta e Hoste, 2008; Sotomaior et al. 2009). Portanto, como os indivíduos susceptíveis são a minoria do rebanho, mas são os que manifestam enfermidade clínica e demandam maiores custos para controle da verminose (Sotomaior et al. 2009), sua correta identificação e descarte representaria economia importante para o produtor, diminuiria a necessidade de tratamentos antihelmínticos e, com isso, a pressão de seleção de parasitos resistentes.

Como a resistência aos parasitos é uma característica poligênica, a seleção fenotípica é uma estratégia menos arriscada do que a seleção de animais portadores de um gene específico (Kemper et al., 2009). A análise de cluster mostrou-se como um método eficaz de agrupamento dos animais em resistentes e susceptíveis, conforme já havia sido demonstrado por Schmidt (2001) e Sotomaior (2002), devido à possibilidade de agregar mais de uma variável na análise e do ponto de corte entre animais resistentes e susceptíveis ser atribuído pelo próprio teste.

O uso de mais de um marcador concomitantemente tem o objetivo de enquadrar animais dentro dos grupos resistente e susceptível com maior acurácia. Quando mais de um marcador foi utilizado para a seleção dos animais, observou-se que o grupo susceptível era o mesmo formado em todas as hipóteses analisadas, exceto no agrupamento a partir do OPG e da lgG específica. Assim, tanto o número de eosinófilos circulantes quanto a absorbância para lgE específica poderiam ser utilizados como marcadores juntamente com o OPG. Neste caso, o uso da lgE seria mais vantajoso, uma vez que o teste de enzima-imunoensaio apresenta a leitura automatizada, permite a estocagem das amostras por longos períodos e a 
análise de um grande número de animais ao mesmo tempo (Douch et al., 1995).

O uso isolado de um marcador imunológico para identificação de animais resistentes somente foi possível com 0 eosinófilo. Isto pode ser explicado, pois o número de eosinófilos sanguíneos foi a variável imunológica que teve maior correlação com o OPG $(r$ $=-0,64$ ) e o único marcador imunológico que mostrou diferenças significativas na média do grupo resistente e susceptível. Como os valores de eosinófilos permaneceram $46 \%$ constantes entre todas as coletas realizadas, a amostragem do lote poderia ser realizada a qualquer momento do período seco das ovelhas, sem necessidade de esperar o pico de verminose. Entretanto, Woolaston et al. (1996) desaconselharam a seleção indireta pelo eosinófilo pelo fato da técnica de contagem ser trabalhosa e pela característica apresentar menor herdabilidade que o OPG.

Os valores de absorbância para IgG anti-H.c. mostraram-se muito variáveis entre os animais acompanhados, sobretudo naqueles classificados como resistentes pelo OPG. Isto resultou na baixa correlação obtida entre estas variáveis. Considerável variação na resposta imune dos ovinos aos helmintos gastrintestinais também foi relatada por outros autores (Shaw et al., 1997; Gómez-Muñhoz et al.,1998). A variabilidade do comportamento da $\lg G$ anti-H.c. observada neste trabalho impediu seu uso como caráter de identificação de animais resistentes à verminose, uma vez que tanto animais de alto quanto de baixo OPG apresentaram altos níveis séricos de lgG específica.

A dificuldade em identificar ovinos resistentes indiretamente pelos níveis de IgG anti-H.c. no rebanho estudado não era esperada, tendo em vista a existência de programas de seleção de ovinos resistentes às parasitoses baseados nesta característica. Segundo Douch et al. (1995), a seleção indireta pela IgG teria $51-67 \%$ da eficiência da seleção direta pelo OPG. Contudo, os mesmos autores encontraram maiores diferenças no nível de IgG sérica entre grupos de grande distância genética, ou seja, linhas de animais susceptíveis e resistentes, selecionadas por várias gerações. É possível que quando se pretende identificar animais resistentes a partir de um rebanho comum, que não tenha sido pré-selecionado, a resposta imune seja mais variável dentro de um mesmo gupo. McEwan et al. (1994) estudaram a progênie dos cinco carneiros com os maiores níveis de IgG anti-Trichostrongylus colubriformis de um rebanho não selecionado e dos cinco com menores níveis. A progênie do grupo de maior resposta imune mostrou maiores níveis de $\lg G$ específica sérica, bem como maior ganho de peso. Entretanto, não foi observada divergência entre o OPG das duas linhas. Isso pode indicar uma menor relação entre $\lg$ e OPG em rebanhos que não tenham sido previamente selecionados para resistência.

Outro fator a ser levado em consideração é que os ovinos utilizados neste trabalho eram provenientes de um rebanho em que se praticavam cruzamentos absorventes para a raça Suffolk, considerada mais sensível às parasitoses gastrintestinais em relação a outras raças ovinas como Texel (Sayers et al. 2007); Guf Coast Native (Amarante et al., 1999; Shakya et al., 2009); lle de France (Amarante et al., 2004) e Santa Inês (Rosalinski-Moraes et al., 2001; Amarante et al., 2004). Baixos níveis séricos de $\lg G$ e $\lg E$ foram obtidos em ovinos Suffolk após desafio parasitário por Sayers et al. (2007) e Shakya et al. (2009), indicando que outros critérios possam ser mais 
seguros para indicar indiretamente a carga parasitária do que a mensuração das imunoglobulinas séricas em ovinos desta raça.

\section{CONCLUSÃO}

A identificação de ovelhas resistentes ou sensíveis à verminose gastrintestinal pode ser realizada pelo OPG ou, indiretamente, pelo número de eosinófilos periféricos. Para aumentar a acurácia da seleção, tanto o número de eosinófilos circulantes quanto a $\lg \mathrm{E}$ específica podem ser utilizados concomitantemente com o marcador parasitológico. A IgG anti-Haemonchus não se mostrou um bom critério de seleção.

\section{AGRADECIMENTO}

A Richard Shaw, do AgResearch Hopkirk, Nova Zelândia, por fornecer os anticorpos monoclonais anti-lgE ovina YD3 e XB6. Ao Tenente Mário Barbosa, do Quartel General da V Região Militar em Curitiba, pela cessão dos ovinos e apoio na realização deste trabalho.

\section{REFERÊNCIAS}

AMARANTE, A.F.; CRAIG, T.M.; RAMSEY, W.S. et al. Nematode burdens and cellular responses in the abomasal mucosa and blood of Florida Native, Rambouillet and crossbreed lambs. Veterinary Parasitology, v.80, p.311324, 1999.

AMARANTE, A.F.T.; BRICARELLO, P.A.; ROCHA, R.A. et al. Resistance of Santa Ines, Suffolk and lle de France sheep to acquired gastrointestinal nematode infections. Veterinary Parasitology, v.120, p.91-106, 2004.

AMARANTE, A.F.T. Resistência genética a helmintos gastrointestinais. In: SIMPÓSIO DA SOCIEDADE BRASILEIRA DE

MELHORAMENTO ANIMAL, 5., 2004,

Pirassununga. Anais... Pirassununga: SBMA. Disponível em:

<http://www.sbmaonline.org.br/anais/v/palestras/ palest14.pdf>. Acesso em: 31 set. 2009.
BISSET, S.A; VLASSOFF, A; DOUCH, P.G.C. et al. Nematode burdens and immunological responses following natural challenge in Romney lambs selectively bred for low or high faecal worm count. Veterinary Parasitology, v.61, p.249-263, 1996.

DOUCH, P.G.C.; GREEN, R.S.; MORRIS, C.A. et al. Genetic and phenotypic relationships among anti-Trichostrongylus colubriformis antibody level, faecal egg count and body weight traits in grazing Romney sheep. Livestock Production Science, v.41, p.121-132, 1995.

DOUCH, P.G.C.; GREEN, R.S.; MORRIS, C.A. et al.Phenotypic markers for selection of nematode-resistant sheep. International Journal for Parasitology, v.26, n.8/9, p.899911, 1996.

GOMES, A. Resposta Técnica. Brasília: Ministério da Ciência e Tecnologia, Sistema Brasileiro de Respostas Técnicas, 2006. Disponível em:

<http://sbrt.ibict.br/upload/sbrt1885.pdf>. Acesso: 21 jan. 2007.

GORDON, H.M.L.; WHITLOCK, H.V. A new technique for counting nematode eggs in sheep faeces. Journal of the Council for Scientific and Industrial Research, v.12, p.50, 1939.

GRANADOS, L.B.C.; DIAS, A.J.B.; SALES, M.P. Aspectos gerais da reprodução de ovinos e caprinos. Capacitação dos técnicos e produtores do Norte e Noroeste Fluminense em Reprodução de Caprinos e Ovinos.

Campos de Goytacazes: PROEX/UENF, 2006. 54 p. Disponível em:

<http://www.capritec.com.br/pdf/reproducaodeov inosecaprinos.pdf> Acesso: 24 ago. 2009.

HOUDIJK, J.G.M.; KYRIAZAKIS, I.; JACKSON, F. et al. Can an increased intake of metabolizable protein affect the periparturient relaxation in immunity against Telardosagia circumcincta in sheep. Veterinary Parasitology, v.91, p.43-62, 2000.

JAIN, N.C. Essentials of veterinary hematology. Philadelphia: Lea \& Febiger, 1993. 417p.

KEMPER, K.E.; ELWIN, R.L.; BISHOP, S.C. et al. Haemonchus contortus and Trichostrongylus colubriformis did not adapt to long-term exposure to sheep that were genetically resistant or susceptible to nematode infections.

International Journal for Parasitology, v.39, p.607-614, 2009.

LIMA, A.O.; SOARES, J.B.; GRECO, J.B. et al. Métodos de laboratório aplicados à clínica: técnica e interpretação. 6.ed., Rio de Janeiro: Guanabara Koogan, 1985. 107 p. 
Mac FARLANE, J.C.W.; CECIL, G.W. Eosinophil counting: a modification of Pilots method. British Medical Journal, v.2, p.1187, 1951.

McEWAN, J.C.; DODDS, K.G.; GREER, G.J. et al. Preliminary results from intensive selection based on host antibody level to larval nematode antigens in sheep. In: ANNUAL MEETING OF THE NEW ZEALAND SOCIETY FOR PARASITOLOGY, 23., ,1994. Proceedings... Wellington: The New Zealand Society for Parasitology Inc., 1994. p.50.

O'CONNOR, L.J.; WALKDEN-BROWN, S.W.; KAHN, L.P. Ecology of the free-living stages of major trichostrongylid parasites of sheep.

Veterinary Parasitology, v.142, n.1-2, p.1-15, 2006.

Organizacion de las Naciones Unidas para la Agricultura y la Alimentacion - FAO, Salud Animal. Resistência a los Antiparasitarios: Estado Actual Énfasis en América Latina. Roma: FAO, 2003. 52p.

PERNTHANER, A.; SHAW, R.J.; McNEILL, M.M. et al. Total and nematode-specific IgE responses in intestinal lymph of genetically resistant and susceptible sheep during infection with Trichostrongylus colubriformis. Veterinary Immunology and Immunopathology, v.104, p.69-80, 2005.

PERNTHANER, A.; COLE, S.A.; MORRISON, L. et al. Cytokine and antibody subclass responses in the intestinal lymph of sheep during repeated experimental infections with nematode parasite Trichostrongylus colubriformis. Veterinary Immunology and Immunopathology, v.114, p.135-148, 2006.

PFEFFER, A.; SHAW, R.J.; GREEN, R.S. et al. The transfer of maternal $\lg E$ and other Immunoglobulins specific for Trichostrongylus colubriformis larval excretory/secretory product to the neonatal lamb. Veterinary Immunology and Immunopathology, v.108, p.315-323, 2005.

ROSALINSKI-MORAES, F.; THOMAZSOCCOL, V.; ROSSI JR, P. et al.

Suscetibilidade de ovinos suffolk e santa inês à infecção natural por tricostongilídeos. Archives of Veterinary Science, v.6, n.2, p.63-69, 2001.

ROSALINSKI-MORAES, F.; MINOZZO, J.C.; THOMAZ-SOCCOL,V. Production of somatic extract of adult Haemonchus contortus and its use in an indirect Enzyme-linked Immunosorbent assay for detection of ovine immunoglobulin $\mathrm{G}$. Archives of Veterinary Science, v.13, p.118125, 2008.
RUGAI, E.; MATTOS, T.; BRISOLA, A.P. Nova técnica para isolar larvas de nematóides das fezes - Modificação do método de Baermann. Revista do Instituto Adolfo Lutz, v.14, p.5-8, 1954.

SAYERS, G.; GOOD, B.; HANRAHAN, J.P. et al. Breed differences in mucosal ans systemic antibody response to nematode infection in sheep: an important role for IgE? Parasitology, v.135, p.71-80, 2007.

SCHMIDT, E.M.S.; LOCATELLI-DITTRICH, R.; THOMAZ-SOCCOL, V. et al. Pesquisa de marcadores parasitológicos e hematológicos de resistência ao parasitismo gastrintestinal em cordeiros. Arquivos de Ciências Veterinárias e Zoologia UNIPAR, v.4, n.1, p.55-64, 2001.

SHAKYA, K.P.; MILLER, J.E.; HOROHOV, D.W. A Th2 type immune response is associated with increased resistance to Haemonchus contortus in naturally infected Gulf Coast Native lambs. Veterinary Parasitology, v.163, p.57-66, 2009.

SHAW, R.J.; GRIMMETT, D.J.; DONAGHY, M.J. et al. Production and characterisation of monoclonal antibodies recognising ovine $\mathrm{lgE}$. Veterinary immunology and Immunopathology, v.51, n.3-4, p.235-251, 1996.

SHAW, R.J.; McNEILL, M.M.; GATEHOUSE, T.K. et al. Quantification of total sheep lgE concentration using anti-ovine $\mathrm{IgE}$ monoclonal antibodies in an enzyme immunoassay.

Veterinary immunology and Immunopathology, v.57, p.253-265, 1997.

SHAW, R.J.; GATEHOUSE, T.K.; McNEILL, M.M. Serum IgE responses during primary and challenge infections of sheep with Trichostrongylus colubriformis. International Journal for Parasitology, v.28, p.293-302, 1998.

SHAW, R.J.; MORRIS, C.A.; GREEN, R.S. et al. Genetic and phenotypic relationships among Trichostrongylus colubriformis - specific immunoglobulin E, anti - Trichostrongylus colubriformis antibody, immunoglobulin $\mathrm{G}_{1}$, faecal egg count and body weight traits in grazing Romney lambs. Livestock Production Science, v.58, p.25-32, 1999.

SOTOMAIOR, C. Estudo de caracteres que possam auxiliar na identificação de ovinos resistentes e susceptíveis às helmintoses gastrintestinais. In: CONGRESSO BRASILEIRO DE ESPECIALIDADES EM MEDICINA VETERINÁRIA, 1., 2002, Curitiba. Anais... Curitiba: SPMV, 2002. p.90-94. 
SOTOMAIOR, C.S.; ROSALINSKI-MORAES,F.; SOUZA, F.P. et al. Parasitoses

Gastrintestinais dos Ovinos e Caprinos Alternativas de Controle. Série Informação Técnica, n. 80. Curitiba: Instituto EMATER, 2009. $36 \mathrm{p}$.

TEREFE, G.; LACROUX, C.; ANDREOLETTI, O. et al. Immune response to Haemonchus contortus infection in susceptible (INRA 401) and resistant (Barbados Black Belly) breeds of lambs. Parasite Immunology, v.29, n.8, p.415424, 2007.

THOMAZ-SOCCOL, V.; SOUZA, F.P.; SOTOMAIOR, C. et al. Resistance of gastrointestinal nematodes of anthelmintics in sheep (Ovies aries). Brazilian Archives of Biology and Technology, v.47, p.41-47, 2004.

TIZARD, I.R. Imunologia Veterinária - Uma Introdução. 8.ed. São Paulo: Elsevier, 2009. $520 \mathrm{p}$.

TORRES-ACOSTA, J.F.J; HOSTE, H.

Alternative or improved methods to limit gastrointestinal parasitism in sheep and goats. Small Ruminant Research, v.77, n.2, p.159-173, 2008.
UENO, H.; GONÇALVES, P.C. Manual para diagnóstico das helmintoses de ruminantes. 3.ed. Tóquio: Japan International Cooperation Agency, 1994.166p.

VALDERRÁBANO, J.; GOMEZ-RINCÓN, C; URIARTE, J. Effect of nutricional status and fat reserves on the periparturient immune response to Haemonchus contortus infection in sheep. Veterinary Parasitology, v.141, p.122-131, 2006.

WOOLASTON, R.R.; MANUELLI, P.; EADY, S.J. et al. The value of circulating eosinophil count as selection criterion for resistance of sheep to Trichostrongyle parasites. International Journal for Veterinary Parasitology, v.26, n.1, p.123126, 1996. 